IZA DP No. 5223

The Contribution of Social Transfers to the Reduction of Poverty

Nicholas T. Longford

Catia Nicodemo

September 2010 


\title{
The Contribution of Social Transfers to the Reduction of Poverty
}

\author{
Nicholas T. Longford \\ SNTL and Universitat Pompeu Fabra \\ Catia Nicodemo \\ Universitat Autònoma de Barcelona \\ and IZA
}

\section{Discussion Paper No. 5223 \\ September 2010}

\author{
IZA \\ P.O. Box 7240 \\ 53072 Bonn \\ Germany \\ Phone: +49-228-3894-0 \\ Fax: +49-228-3894-180 \\ E-mail: iza@iza.org
}

\begin{abstract}
Any opinions expressed here are those of the author(s) and not those of IZA. Research published in this series may include views on policy, but the institute itself takes no institutional policy positions.

The Institute for the Study of Labor (IZA) in Bonn is a local and virtual international research center and a place of communication between science, politics and business. IZA is an independent nonprofit organization supported by Deutsche Post Foundation. The center is associated with the University of Bonn and offers a stimulating research environment through its international network, workshops and conferences, data service, project support, research visits and doctoral program. IZA engages in (i) original and internationally competitive research in all fields of labor economics, (ii) development of policy concepts, and (iii) dissemination of research results and concepts to the interested public.
\end{abstract}

IZA Discussion Papers often represent preliminary work and are circulated to encourage discussion. Citation of such a paper should account for its provisional character. A revised version may be available directly from the author. 
IZA Discussion Paper No. 5223

September 2010

\section{ABSTRACT}

\section{The Contribution of Social Transfers to the Reduction of Poverty ${ }^{\star}$}

We interpret social transfers broadly as a set of measures to reduce or relieve poverty, and study how well this purpose is served in the countries that participated in the European Union Statistics on Income and Living Conditions in 2007. Motivated by the findings, we characterise a social transfer system in a country by its potential and effectiveness, and compare the countries for a range of definitions of the poverty threshold. The methods are also applied to two subpopulations of household types.

JEL Classification: $\quad$ I32, C83

Keywords: effectiveness of social transfers, equivalized household income, EU-SILC database, potential of social transfers, poverty gap

Corresponding author:

Catia Nicodemo

Universitat Autonoma de Barcelona

Department of Applied Economics

Campus Bellaterra

08193 Bellaterra (Cerdanyola)

Spain

E-mail: catia.nicodemo@uab.cat

\footnotetext{
* This paper describes part of the research conducted by the authors during their visit in le Centre d'Etudes de Populations, de Pauvreté et de Politiques Socio-Economiques/International Network for Studies in Technology, Environment, Alternatives and Development (CEPS/INSTEAD) in Differdange, Luxembourg, under the Access to Research Infrastructure (ARI) Programme of the European Commission (6th Framework Programme, Contract No. 026040). The first author's work was also supported by the Grant No. SEJ2006-13537 from the Spanish Ministry of Science and Technology.
} 


\section{Introduction}

Poverty is an undesirable feature of every society, and its alleviation is regarded as an important function of the government and related institutions. In this paper, we study how well the social transfers fulfil this role. The ideal is that if all social transfers were discarded there would be an appreciable level of poverty, but when the social transfers are regarded as a component of household income, poverty is greatly reduced. We assess how close a system of social transfers is to such an ideal. We analyze the (cross-sectional) data from the European Union Statistics on Income and Living Condition (EU-SILC) from 2007 to evaluate the consequences of the social transfers on the poverty status of individuals and on the change in the poverty gap of those who would be classified as poor if all social transfers were withheld.

Large differences prevail among the countries of the European Union in social protection expenditure as a percentage of GDP; Eurostat (2009). In 2006, social protection expenditure as a percentage of GDP was above 30\% in France (31.1\%), Sweden (30.7\%) and Belgium (30.1\%), and below $15 \%$ in Latvia (12.2\%), Estonia (12.4\%), Lithuania $(13.2 \%)$ and Romania (14.0\%). These disparities reflect differences in living standards, but are also indicative of the diversity of the social protection systems and of the demographic, economic, social and institutional structures specific to each country. There are many policies that national governments can institute to reduce poverty. The Lisbon Summit in 2000 gives directives to the member states to invest in people and build an effective welfare system to reduce the high poverty rates across Europe. Poverty reduction and income distribution are not the only purposes of social transfers systems, as argued by Atkinson (1995). Child and disability benefits and tax allowances are also part of the social transfer system, but their role is not solely to reduce poverty.

Comparing the effectiveness in alleviating poverty is not easy, because some countries spend more on social protection than others and countries use different instruments. Eurostat (2010) concludes that the impact of social benefits in the mid-2000's was weakest in Bulgaria and several Mediterranean Member States (Greece, Spain, Italy and Cyprus). In contrast, more than half of those at risk of poverty in Hungary, Sweden, Finland, Ireland and Denmark were removed from this risk as a result of social transfers. The results of our study are largely in agreement with these conclusions. 
Eurostat (2010) finds that social transfers had a significant impact on reducing the risk of poverty among children (under the age of 18). They removed $39.4 \%$ of children from the risk of poverty in the EU27 in 2007, more that for all the age groups (34.6\%). Social transfers had a relatively important impact on children in Cyprus, Germany and Estonia, where the proportion of children taken out of risk was at least ten percent higher than the corresponding share for the whole population. In the Netherlands, Bulgaria, Portugal, Lithuania, Greece, Slovakia, Hungary, the Czech Republic and Belgium, the proportion of persons removed from the risk of poverty as a result of social transfers was higher across the whole population than it was for children.

Research on how the income distribution is changed as a result of social transfers is less common. Until the seminal contribution by Esping-Andersen (1990), most empirical work on distributive impacts of welfare programmes had relied on comparing the amount of social security expenditure with its distributive outcomes. The reduction of poverty by social assistance payments is assessed by several measures, such as the headcount ratio, poverty gap ratio, FGT2 (Squared Poverty Gap Index) and the Sen index of poverty.

Hölsch and Kraus (2004) investigated the relationship between the degree of centralization and the distributive outcomes of social assistance schemes in European countries. They classify the schemes in the EU15 countries according to features related to centralization, and identify five groups or systems. Their results provide some evidence that extremely centralized systems are more effective with regard to redistribution of income than extremely decentralized schemes. They point out that for systems with a medium degree of centralization, the hypothesis that greater decentralization leads to more effectiveness is not supported. A commonly adopted approach to measuring efficiency, due to Beckerman (1979a, b), is based on the aggregate poverty gap, defined as the sum of the individual income shortfalls from the poverty line. A system is called effective if the aggregate poverty gap is greatly reduced by the social transfers.

Different studies address the performance of the social protection systems of the European Union countries in reducing poverty both in relative and absolute terms. Morissens and Sainsbury (2002) analyze the incidence of poverty and poverty reduction for the entire population and vulnerable groups. They assess the effectiveness 
of social transfers by comparing the population's economic situation before and after taxes and transfers, and use relative and absolute measures of poverty reduction. They conclude that during the 1990s the poverty rate increased in most countries and in many instances for vulnerable groups in particular, with the exception of the elderly. They also find large differences in how the social protection systems of the countries reduce poverty both in relative and absolute terms. The relative effectiveness of many countries decreased during the decade.

The role of social transfers in Europe is discussed also by Cohen-Solal et al., (1999), Marlier et al., (1999) and Eardley et al. (1996). Atkinson (2000) shows that the European countries that reduce poverty most tend to have higher social spending. Many studies relate the country's system to its method of administration, share of GDP, and the like. The EU-SILC database contains information about disposable income after and before the social transfers, with or without the pension benefits (variables HY020, HY022 and HY023), so it is well suited for such studies.

We define the potential of a (national) social transfer system by comparing its total (or average) amount with the total (or average) shortfall of household income, commonly referred to as the poverty gap. In agreement with Beckerman (1979a, b), we define effectiveness of the system as the fraction of the total amount of social transfers that resulted in the reduction of the poverty gap.

The next section describes the amounts involved in the social transfers in the 26 countries that participated in the cross-sectional component of EU-SILC in 2007 and summarizes their impact by the percentages of households that would be classified as poor or not poor differently, depending on whether social transfers are discarded or retained as a component of household income. The following section studies the impact of the social transfers on the poverty gap. Section 4 defines and evaluates the potential and effectiveness of the national social transfer systems. Section 5 applies these methods to two subpopulations that are associated with greater need for social transfers: single-parent households and households with many children.

The poverty threshold is conventionally set at $60 \%$ of the national median equivalized household income $(e H I)$. We respond to the concern about the poor foundation or arbitrariness of the setting of this percentage by evaluating all quantities related to poverty for a range of threshold percentages. We present the results in the form of 
graphs, in which the poverty rate, the poverty gap and similar quantities are represented by curves, functions of the poverty threshold percentage.

Throughout, per-capita values indicate (weighted) sample averages for an equivalized unit of a household. We use the OECD-modified scale (Hagenaars, de Vos and Zaidi, 1994), according to which the equivalized size of a household is determined by counting one of its adult members (e.g., the head) as a unit, every other adult as 0.5, and every child (member up to 14 years of age) as 0.3. For example, the equivalized size of a household with two adults and two children is $1.0+0.5+2 \times 0.3=2.1$. A social transfer of 10500 Euro to such a household amounts to 10500/2.1 = 5000 Euro per equivalized unit. In our analysis, we regard pensions and survivor's benefits as elements of social transfer.

\section{The extent of social transfers}

In this section, we summarize the country's social transfer system by estimating the percentage of households that receive social transfers, the percentage of individuals in these households, the average size of a transfer per individual and its size relative to the country's median eHI. These summaries are displayed in Table 1. The table shows that a majority of the households and individuals receive some social transfers in most countries; the exceptions are Greece and Spain, and Poland by a narrow margin, and only for the number of households. At the other extreme, $91.2 \%$ of individuals in Ireland receive social transfers. The estimated percentage of individuals who receive social transfers is greater than the percentage of households in all countries, by between $3.1 \%$ (Greece) and $14.5 \%$ (Germany). The social transfers are most generous in Ireland and Norway, where they exceed 10000 Euro per capita, and they fall short of 1000 Euro in most eastern European countries and Greece. It might seem more equitable to relate the amount of social transfers per capita to the median eHI or a similar quantity. By this measure, the social transfers are on average most modest in Greece, where they constitute only $8.3 \%$ of the median eHI. Hungary $(48.9 \%)$ and Ireland $(47.7 \%)$ have the most generous social transfers, reaching nearly half the level of the median income.

It is plausible that some social transfers are not distinguished from wages in some countries. For example, various allowances, such as for children and disability, are 
Table 1: Summaries of the social transfers in the countries in EU-SILC in 2007.

\begin{tabular}{|c|c|c|c|c|c|c|c|}
\hline & \multirow[b]{2}{*}{ Country } & \multicolumn{2}{|c|}{ Sample } & \multicolumn{2}{|c|}{ \% rec. soc. transfers } & \multicolumn{2}{|c|}{ Average } \\
\hline & & H-holds & Indiv-s & H-holds & Indiv-s & Euro & $\%$ medHI \\
\hline $\mathrm{AT}$ & Austria & 16684 & 53706 & 63.44 & 76.90 & 6016.41 & 32.98 \\
\hline $\mathrm{BE}$ & Belgium & 15493 & 49135 & 66.96 & 80.06 & 6531.93 & 37.19 \\
\hline $\mathrm{CY}$ & Cyprus & 10630 & 40082 & 73.85 & 82.38 & 3237.48 & 20.25 \\
\hline $\mathrm{CZ}$ & Czech Republic & 23059 & 69875 & 63.54 & 72.70 & 1483.76 & 27.38 \\
\hline $\mathrm{DE}$ & Germany & 31709 & 89641 & 60.83 & 75.34 & 5000.16 & 28.31 \\
\hline DK & Denmark & 14887 & 47567 & 77.84 & 86.70 & 6497.93 & 27.84 \\
\hline $\mathrm{EE}$ & Estonia & 14372 & 51562 & 66.16 & 79.05 & 991.20 & 22.29 \\
\hline ES & Spain & 34586 & 118364 & 30.15 & 33.43 & 1475.20 & 12.38 \\
\hline GR & Greece & 14793 & 48809 & 27.49 & 30.57 & 833.17 & 8.33 \\
\hline $\mathrm{IT}$ & Italy & 52772 & 166776 & 51.36 & 58.15 & 2002.83 & 13.35 \\
\hline FI & Finland & 27454 & 91784 & 73.79 & 84.59 & 6622.05 & 35.41 \\
\hline FR & France & 25907 & 83301 & 62.80 & 74.10 & 5906.95 & 35.66 \\
\hline $\mathrm{HU}$ & Hungary & 22297 & 73831 & 71.28 & 81.677 & 1924.40 & 48.90 \\
\hline IE & Ireland & 13691 & 45235 & 86.50 & 91.20 & 10558.70 & 47.67 \\
\hline IS & Iceland & 8651 & 31809 & 63.13 & 71.31 & 5076.30 & 17.68 \\
\hline $\mathrm{LT}$ & Lithuania & 12777 & 41749 & 58.05 & 66.77 & 755.28 & 23.05 \\
\hline $\mathrm{LU}$ & Luxembourg & 10419 & 35337 & 66.77 & 79.42 & 8529.41 & 28.54 \\
\hline $\mathrm{LV}$ & Latvia & 11209 & 37587 & 70.69 & 80.69 & 809.96 & 24.98 \\
\hline NL & the Netherlands & 25905 & 83159 & 68.28 & 80.44 & 3469.76 & 19.06 \\
\hline $\mathrm{NO}$ & Norway & 15132 & 48926 & 77.34 & 87.01 & 10253.51 & 35.65 \\
\hline PL & Poland & 42852 & 166050 & 48.85 & 58.15 & 930.79 & 26.58 \\
\hline $\mathrm{PT}$ & Portugal & 11691 & 39265 & 60.52 & 69.10 & 1447.80 & 19.15 \\
\hline $\mathrm{SE}$ & Sweden & 18126 & 58076 & 72.02 & 83.08 & 7088.57 & 38.21 \\
\hline SI & Slovenia & 28570 & 111478 & 75.62 & 83.81 & 3573.14 & 35.19 \\
\hline SK & Slovakia & 14858 & 57638 & 69.26 & 79.93 & 959.83 & 24.74 \\
\hline UK & United Kingdom & 21942 & 66824 & 59.13 & 71.66 & 6162.07 & 29.41 \\
\hline
\end{tabular}


Table 2: Example of a summary of poverty status before and after social transfers. The figures are in percentages, based on a fictitious data.

\begin{tabular}{lcc}
\hline & \multicolumn{2}{c}{ After } \\
\cline { 2 - 3 } Before & Poor & Not poor \\
\hline Poor & 4.5 & 6.8 \\
Not poor & 1.2 & 87.5 \\
\hline
\end{tabular}

clearly recognized when paid directly to the recipients, but may be disregarded when they are credited in the form of higher threshold for income that is not taxed. With the large number of countries studied, it is beyond the scope of this paper to account for these differences in the national tax systems. (The local taxation would also have to be taken into account.) A similar issue arises when we consider the 'alternative world' in which no social transfers are distributed. In this setting, the tax liabilities of a household are also changed, and so, at least in principle, part of a benefit (payment) received in the 'real world' should be set aside for additional taxes. However, in the alternative world the tax revenue authority would adjust the tax rules to reflect the reduced income of the country's households. In brief, the rules for taxation cannot be regarded as fixed, and we do not venture to second-guess how they would be altered in a hypothetical setting. See Duncan et al. (1993) for a related discussion.

We assume that the purpose of a social transfer system is to distribute funds in a targeted fashion, so that, ideally, their recipients would have been poor, or classified as poor, if they did not receive them, but after receiving them would not be classified as poor, or their eHI would be much closer to the poverty threshold. Therefore, we classify each household and individual according to two poverty-related criteria: without social transfers and with them. This classification is summarized by a $2 \times 2$ table of estimates of national percentages (rates); see Table 2 for an example. We use the code 0 for being poor and 1 for being not poor, and combine these codes for the poverty status before and after social transfers.

We are particularly interested in the off-diagonal entries $(6.8 \%$ and $1.2 \%$ in Table 2 ), which correspond to switching from being poor without counting social transfers 
to being not poor after counting them (pattern 01), and switching from being not poor without counting social transfers to being poor after counting them (pattern 10). Pattern 10 is plausible because the poverty threshold is increased when some households contribute to its evaluation with income boosted by social transfers. We denote by $r_{01}$ and $r_{10}$ the rates that correspond to the respective patterns 01 and 10 , and by $r_{00}$ and $r_{11}$ the proportions of individuals who are respectively poor and not poor according to both criteria.

A prerequisite for Table 2 is a method of classifying households as poor or not poor. We adopt the established criterion according to which a household, and every one of its members, is classified as poor if their eHI is smaller than a given percentage of the national median eHI (Hagenaars and van Praag, 1985). Instead of the (single) conventional setting of $60 \%$, we estimate the rates of the two 'switch' patterns for a fine grid of threshold percentages in the range $40-80 \%$, acknowledging that although the threshold of $60 \%$ is reasonable, other thresholds could also be considered. Thus, we represent the (national) rates of switching by curves, functions of the threshold percentage. These curves are plotted in Figure 1. In the left-hand panels the estimates of the rates of switching from poverty $\left(r_{01}\right)$ and switching to poverty $\left(r_{10}\right)$ and in the right-hand panels the corresponding relative rates, $r_{01} /\left(r_{01}+r_{00}\right)$ and $r_{10} /\left(r_{10}+r_{11}\right)$, are drawn. The denominators, $r_{01}+r_{00}$ and $r_{10}+r_{11}$, are the respective rates of poverty and its complement, both evaluated without counting the social transfers. They are the constituencies for which the two kinds of switches are possible.

The absolute rates of switching from poverty $\left(100 r_{01} \%\right)$ are highly unstable and they intersect a great deal even at threshold percentages close to $60 \%$, so they are highly sensitive to the setting of this percentage. Although Greece, Italy and Spain have the lowest rates of switching throughout the range of threshold percentages, the rates for several other countries change a great deal in relation to the other countries. For example, Ireland has the highest rate for the lowest threshold percentages, but its rate for the highest percentages is well below the average for the studied countries. The rates for Norway and Sweden are around the average for the smallest threshold percentages, but are among the highest for the threshold near $80 \%$.

The relative rates of switching from poverty, $100 r_{01} /\left(r_{01}+r_{00}\right) \%$, take into account the poverty rate calculated without the social transfers. These rates display much more 



Figure 1: The estimated national rates of switching from and to poverty as a result of social transfers in 2007; poverty threshold percentages $40-80 \%$. 
stability. The countries' curves tend to decrease with the threshold percentage because more extreme poverty (corresponding to lower threshold) is in general easier to identify or target. Just like for the absolute rates, Greece, Italy and Spain have the lowest relative rates of switching from poverty throughout the range of poverty thresholds. Apart from them, we can identify another group of countries with relative rates in the range $40-60 \%$ for the poverty threshold of 40\% (Cyprus, Estonia, Lithuania, Latvia, Poland, Portugal and Slovakia), and the remaining countries (the entire north-west Europe, Czech Republic, Hungary and Slovenia) have distinctly higher relative rates for small poverty thresholds. For higher poverty thresholds, these groups of countries are not separated as clearly but, with only a few exceptions, maintain their ranks. For example, the rate for Slovakia is slightly higher than for Belgium and Luxembourg for the poverty threshold of $80 \%$.

The rates of switching to poverty (bottom panels of Figure 1) are extremely unstable, because they involve operations with relatively small percentages, especially for low poverty thresholds. The relative rates, $100 r_{10} /\left(r_{10}+r_{11}\right) \%$, differ from the absolute rates only slightly, because $r_{11}$ is close to 1.0 for all threshold percentages and all countries. In general, the percentages of switching to poverty, both absolute and relative, are much smaller than for switching from poverty. Most households classified as not poor do not rely on social transfers to maintain their prosperity vis-à-vis any reasonable poverty threshold.

\section{Reduction of the poverty gap}

An arguably more refined measure of the impact of social transfers is obtained by comparing the poverty gap based on income with the social transfers ignored and the poverty gap based on income with the transfers included. The poverty gap of a household is defined as zero if the household's eHI exceeds the poverty threshold; otherwise it is equal to the difference of the poverty threshold and the household's eHI:

$$
P G=(P T-e H I)_{+} \cdot
$$

We consider the same range of threshold percentages, 40-80, as in the previous section. The mean poverty gap of a country is then represented by a curve, a function of this percentage. This mean (average) is referred to as the absolute mean poverty gap, to 
distinguish it from the relative mean poverty gap, which is defined as the ratio of the absolute mean poverty gap and the poverty threshold.
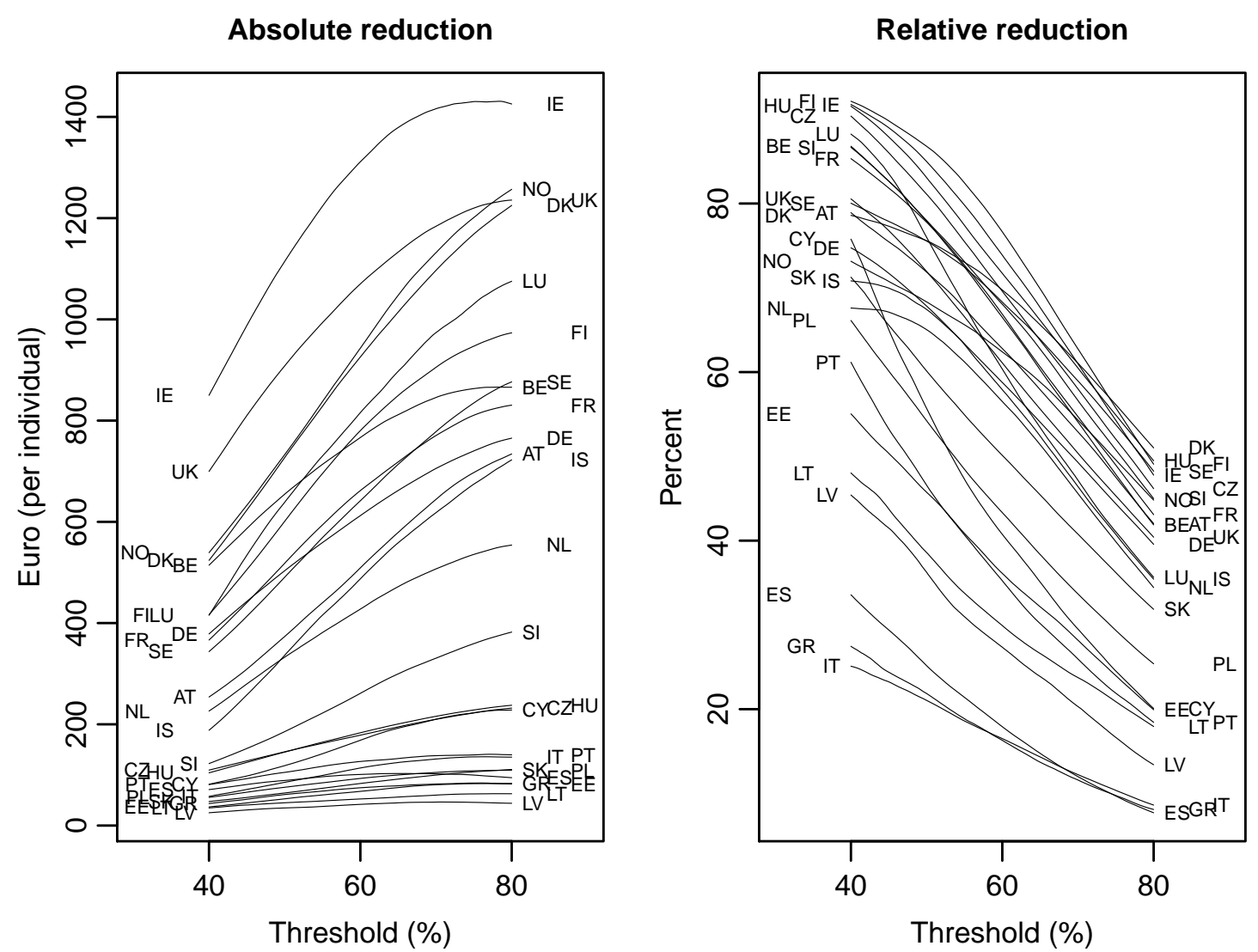

Figure 2: The estimated reductions of the poverty gap that are attributable to the social transfers.

The poverty gap can be evaluated for the income before and after social transfers. The difference (reduction) can be attributed to social transfers. This reduction can be evaluated on the absolute and relative scales; the former is the plain difference, and the latter is this difference divided by the poverty gap before social transfers. The reduction on these two scales is plotted in Figure 2 for the 26 countries in EUSILC in 2007. The reduction on the absolute scale is closely related to the per capita amount of transfers. Ireland has the highest mean reduction, but it is followed by Norway, which has the second highest amount of transfers per capita (see Table 1), only for the threshold percentages near 80. United Kingdom takes the second place for all threshold percentages except in the vicinity of $80 \%$, even though its per capita 
amount of transfers is much smaller than for Norway or Ireland. Countries with much smaller per capita amounts of transfers have much smaller reductions; with small overall amount of transfers only small reductions can be attained. For example, even though the per capita amount of social transfers in Hungary is nearly $50 \%$ of the median eHI, the absolute reduction of the poverty gap is much smaller, 100-200 Euro, than for the countries with much greater median eHI (and much greater absolute poverty gaps). In contrast, high level of social transfers need not result in a substantial reduction of poverty; this happens when a lot of the funds are received by households that would be classified as not poor even if social transfers were not counted. For example, Austria has a higher per-capita amount of social transfers than Germany (6020 Euro versus 5000 Euro). However, the transfers reduce the poverty gap much more in Germany than in Austria for all threshold percentages. Of course, if the poverty gap in a country were low, then it would be very difficult to reduce it, and there would be an upper limit on the amount of reduction. The levels of poverty gap and are much higher than the reduction attained in both countries, but the mean poverty gap in Austria is much lower than in Germany, especially for small thresholds. This provides a rationale to study the relative reduction of the poverty gap, defined as the ratio of the (absolute) reduction and the mean poverty gap.

The right-hand panel of Figure 2 displays the relative reductions of the poverty gap. On the absolute scale, the reduction increases with the threshold percentage, because so does the mean poverty gap. On the relative scale, the reduction decreases because the social transfers tend to be more effective at reducing more extreme poverty. The ranking of the countries closely resembles the ranking according to the relative rates of switching from poverty in the top right-hand panel of Figure 1. Greece, Italy and Spain stand out with the lowest relative reductions, followed by the set of six countries that can be identified more clearly in Figure 1, with the exception of Cyprus for the lower threshold percentages, for which its relative reduction exceeds that of Germany, Iceland, the Netherlands and Norway. Czech Republic and Hungary have among the highest relative reductions, for what might appear to be a relatively small outlay on social transfers; they are small in absolute terms but, especially for Hungary, are large in relation to the national median eHI. Although the relative reduction for Austria 
is uniformly greater than for Germany, the difference is less pronounced than on the absolute scale.

\section{Potential and effectiveness of social transfers}

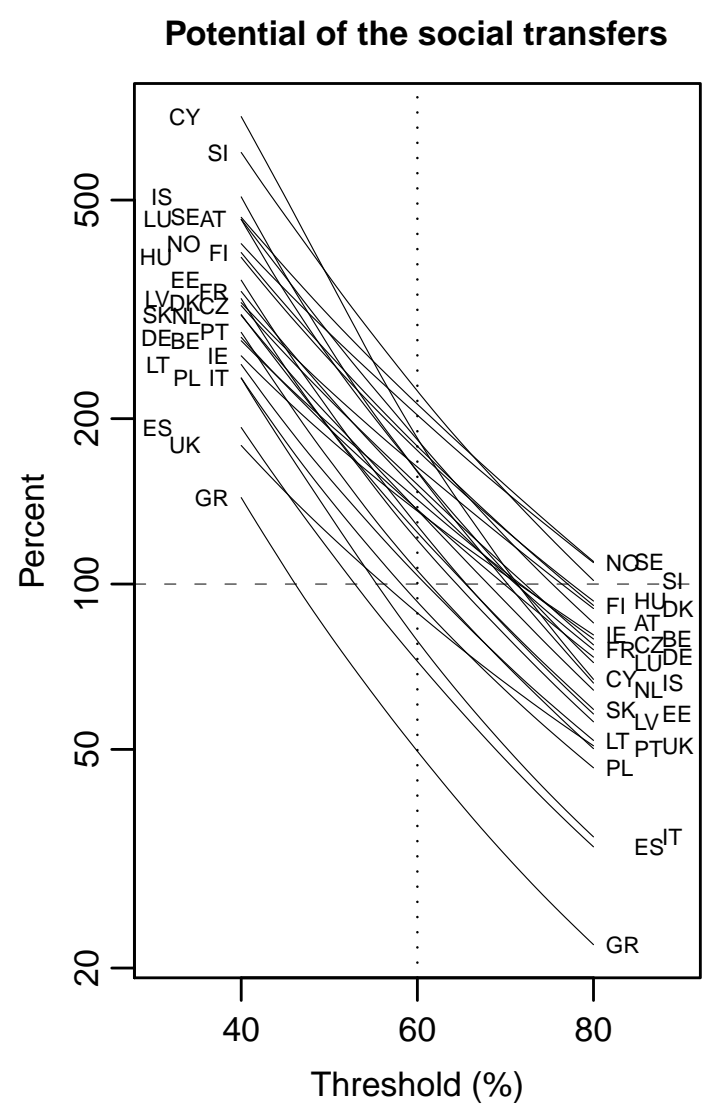

Effectiveness of the social transfers

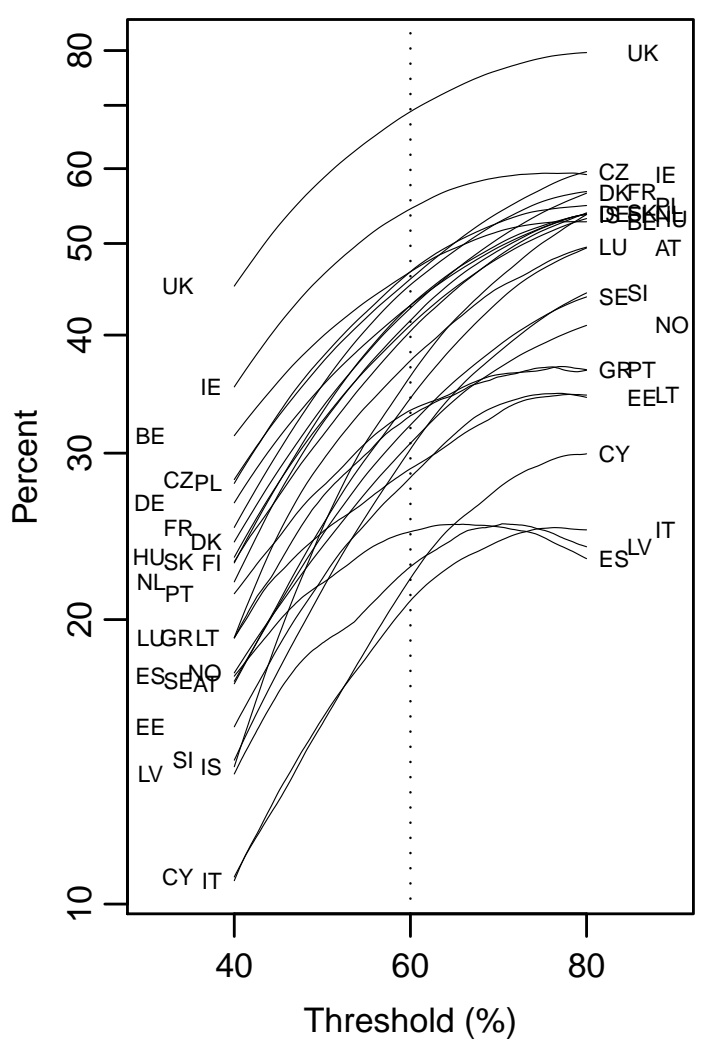

Figure 3: The potential and the effectiveness of the social transfers in the countries in EU-SILC.

We interpret the social transfers as a means of poverty reduction, and reduction of the poverty gap in particular. Therefore, we define the potential of a system of social transfers as the ratio of the total amount of social transfers and the overall poverty gap calculated with the social transfers ignored. This is equal to the ratio of the corresponding per-capita amounts. As the poverty gap is defined with respect to a poverty threshold, we define the potential for the range of threshold percentages $40-$ 80. In these ratios, the numerator (social transfers) is constant, and the denominator 
(poverty gap) increases with the threshold percentage. Therefore the potential is a decreasing function of the threshold percentage.

The estimated national potentials are plotted in the left-hand panel of Figure 3. The potentials, as functions or curves, intersect a great deal, quite a lot even in the vicinity of the conventional threshold of $60 \%$. A straightforward comparison of the countries based on a single percentage is therefore ill-advised. For example, Cyprus has the highest potential for the lowest threshold percentages, but its potential for the highest percentages is only around the average. However, Greece, Italy and Spain, identified earlier as the countries with the lowest amounts of transfers per capita, have the lowest potential, except for United Kingdom, which has the second lowest potential for the threshold percentages close to $40 \%$.

For the poverty threshold set at $40 \%$ of eHI, the potential exceeds $100 \%$ for all the countries. Thus, if allocated with purpose, the social transfers in these countries could easily raise every household's eHI, that is, its national minimum, above $40 \%$ of the median eHI. The social transfers in Norway, Sweden and Slovenia could raise the minimum to a level even above $80 \%$ of the median eHI. Note however, that the social transfers raise the level of the median eHI, and therefore create 'new' poverty, comprising those classified as not poor if all social transfers were withheld and as poor when all social transfers are taken into account. We can characterize the social transfers in a country by the poverty threshold for which the amount of transfers is equal to the poverty gap. This critical threshold percentage is found as the threshold percentage at which the potential is equal to $100 \%$, that is, where the potential curve crosses the horizontal dashed line drawn in Figure 3. The critical threshold percentage is lowest for Greece (46.1\%), followed by Spain (52.9\%) and Italy $(55.4 \%)$; it is equal to $80.4 \%$ for Slovenia, and to $82.9 \%$ for both Norway and Sweden.

The effectiveness of the social transfers is defined as the ratio of the reduction of the mean poverty gap and the amount of transfers per capita. The curves corresponding to the range of threshold percentages $40-80 \%$ are plotted in the right-hand panel of Figure 3. The curves are plotted on the logarithmic scale. Most of the curves increase throughout the range of threshold percentages, rapidly for small threshold percentages, because for higher threshold percentage more transfers are likely to be received by those below the poverty threshold. However, there are some anomalies at the highest 
threshold percentages, for Spain and Latvia in particular, and the curve is flat in the vicinity of the $80 \%$ threshold for several other countries.

The social transfer system in United Kingdom is uniformly the most effective, followed by Ireland for almost the entire range of threshold percentages and Czech Republic for a narrow range around $80 \%$. The lowest effectiveness is attained by Italy for the threshold percentages up to just above $70 \%$, for Cyprus up to $60 \%$, and for Latvia and Spain for threshold percentages above $70 \%$.

A system with a low potential might be expected to be highly effective because a relatively smaller amount of funds is easier to monitor and target at the most deserving cases. For example, the transfers in United Kingdom have a low potential and high effectiveness, and Cyprus has high potential and low effectiveness. However, there are several exceptions to this inverse relationship. For example, Italy and Spain have both low potentials and low effectiveness and Czech Republic has an above-average potential and high effectiveness.

Figure 4 presents an alternative summary of the potential and effectiveness of the national social transfer systems. Each country is represented by a curve of its effectiveness as a function of the potential. The vertical ticks mark the values for the thresholds of 80, 70, 60, 50 and 40\% (from left to right). The countries are divided into four groups, and the curves for the countries for each group are drawn by solid lines against the background of the curves for the other countries drawn by thin dashes. To facilitate comparisons across the groups, the axes in the four panels have identical scales.

For any given value of the potential, the social transfers in the countries in the north and west of Europe are more effective than in the south and in the three former Soviet republics. The systems in the countries in central Europe are about as effective as the systems in the Scandinavian countries, but have a smaller potential. Except for Cyprus, the systems in the southern European (Mediterranean) countries have a low potential, and all of them have low effectiveness. 



Figure 4: The association of potential and effectiveness of the social transfers in the countries in EU-SILC. 


\section{Social transfers to vulnerable subpopulations}

The summaries of the social transfers are well defined in subpopulations of households, and are of particular interest in subpopulations that may be targeted for support or are generally acknowledged as being appropriate recipients of specific income-support programmes. In EU-SILC, we can identify two such subpopulations, single-parent households and households with three or more children. In fact, the former category is defined as single-adult households with at least one child, but we assume that the adult is (in the role of) a parent. In the analysis of such a subpopulation in a country, we use the same definition of the poverty threshold as in the earlier section, based on the entire sample of households. We focus on the changes in the mean poverty gap that can be attributed to social transfers. The rates of switching between poverty states are not suitable summaries because they are very unstable functions of the threshold percentage.

The left-hand panel of Figure 5 compares the mean poverty gaps in the subpopulation of single-parent households and the entire population of a country. Each country is represented by a curve drawn for the poverty gaps defined at the poverty thresholds ranging from $40 \%$ to $80 \%$. The symbol for each country is placed at the coordinates for the national and subgroup mean poverty gaps at $40 \%$. All the curves are increasing and they tend to converge near the top right-hand corner of the diagram. The ends of the curves are uneven, because the countries have different mean poverty gaps at the threshold of $80 \%$. The thin dashes mark the identity line; a curve above the identity indicates that the mean poverty gap of the single-parent households exceeds the overall mean poverty gap in the country. With the sole exception of Denmark, the mean poverty gap for single-parent households is higher than the mean poverty gap for the all the households. Even for Denmark, single-parent households have higher poverty gap from about $61 \%$ threshold on, but its levels are lower than for other countries with similar poverty gaps for all households.

The right-hand panel compares the mean amounts of social transfer for all and single-parent households. The countries' symbols have sizes proportional to the square root of the percentage of the households led by a single parent; these percentages range from $1.8 \%$ for Greece, followed by Slovenia (2.1\%) and Spain and Portugal (2.2\% each), 

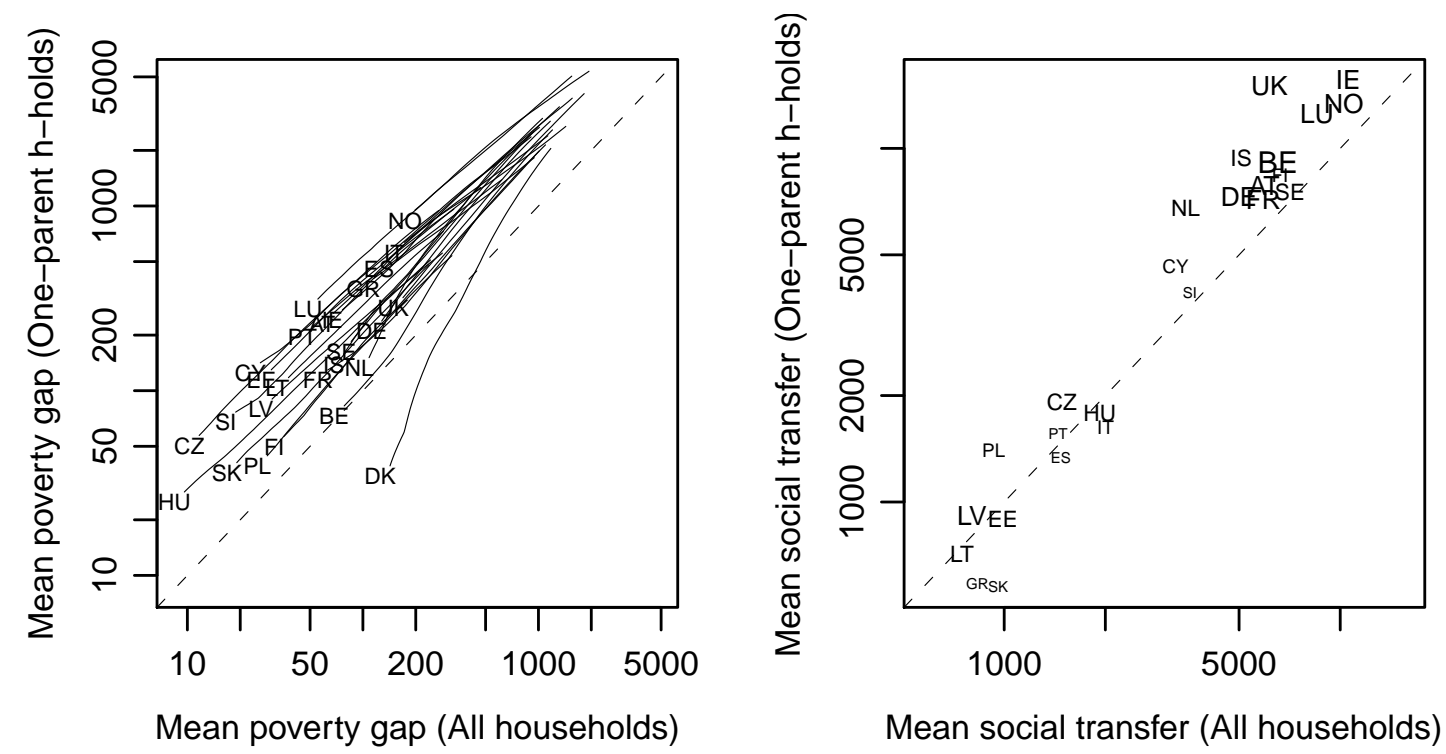

Figure 5: The mean poverty gap and the mean amount of social transfers paid to single-parent and all households.

to $7.1 \%$ for Belgium, preceded by the UK (6.8\%) and Ireland (6.7\%). The symbol for Denmark is omitted from the plot, because it would be completely obscured by the much bigger symbol for Belgium. The sample proportion of single-parent households in Denmark is 3.8\%, similar to Finland (3.6\%) and the Netherlands (3.9\%).

While the mean poverty gap of the single-parent households is greater than the national poverty gap in all countries except Denmark for some threshold percentages, the mean amount of social transfers paid to single-parent households is smaller than the overall mean for several countries, for Greece and Slovakia by the widest margin. However, in countries with greater proportion of single-parent households, the mean amount of social transfers paid to them exceeds the overall mean. These countries include not only all the countries in northern and western Europe, but also the Czech Republic, and Latvia by a narrow margin.

Figure 6 displays the absolute and relative reduction of the poverty gap as functions of the threshold percentage for single-parent households. The greatest absolute reduction is attained by the UK, followed by Ireland and Norway. The East European and Mediterranean countries tend to have smaller reductions. A careful interpretation of these differences is called for because of the interplay of the effectiveness of the social transfer system for the subpopulation, the magnitude of its (mean) poverty gap and 

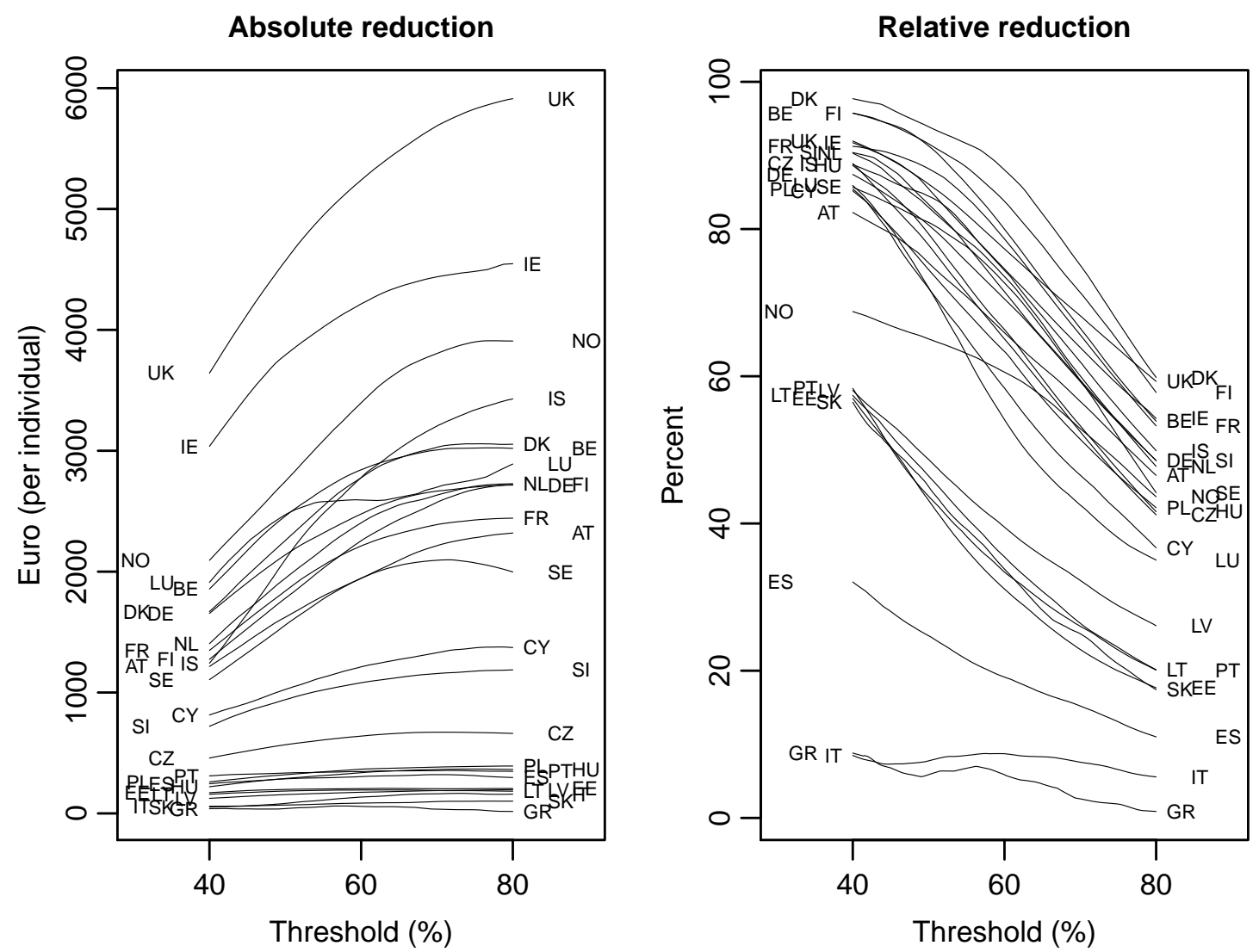

Figure 6: The absolute and relative reduction of the mean poverty gap among the single-parent households in the countries in EU-SILC.

the median eHI in the country. The relative reduction curves in the right-hand panel account for the level of income in the country, but not for the extent of poverty in the subpopulation. The relative reductions are uniformly the smallest for Greece and Italy, followed by Spain. Another group of countries, Slovakia, Portugal and the Baltic countries, can be identified, with the relative reduction around $60 \%$ for the lowest threshold $(40 \%)$ and $20-30 \%$ for the highest threshold (80\%). Although the diagram is bound to be similar to its counterpart for the entire population in Figure 2, there are some notable departures. Unlike in Figure 2, the reduction for the Netherlands is about average for the countries in the north and west of Europe, and the reduction in the UK is relatively much greater for single-parent households than for the entire population. In general, the curves in both panels of Figure 6 are coarser than in Figure 2, because 

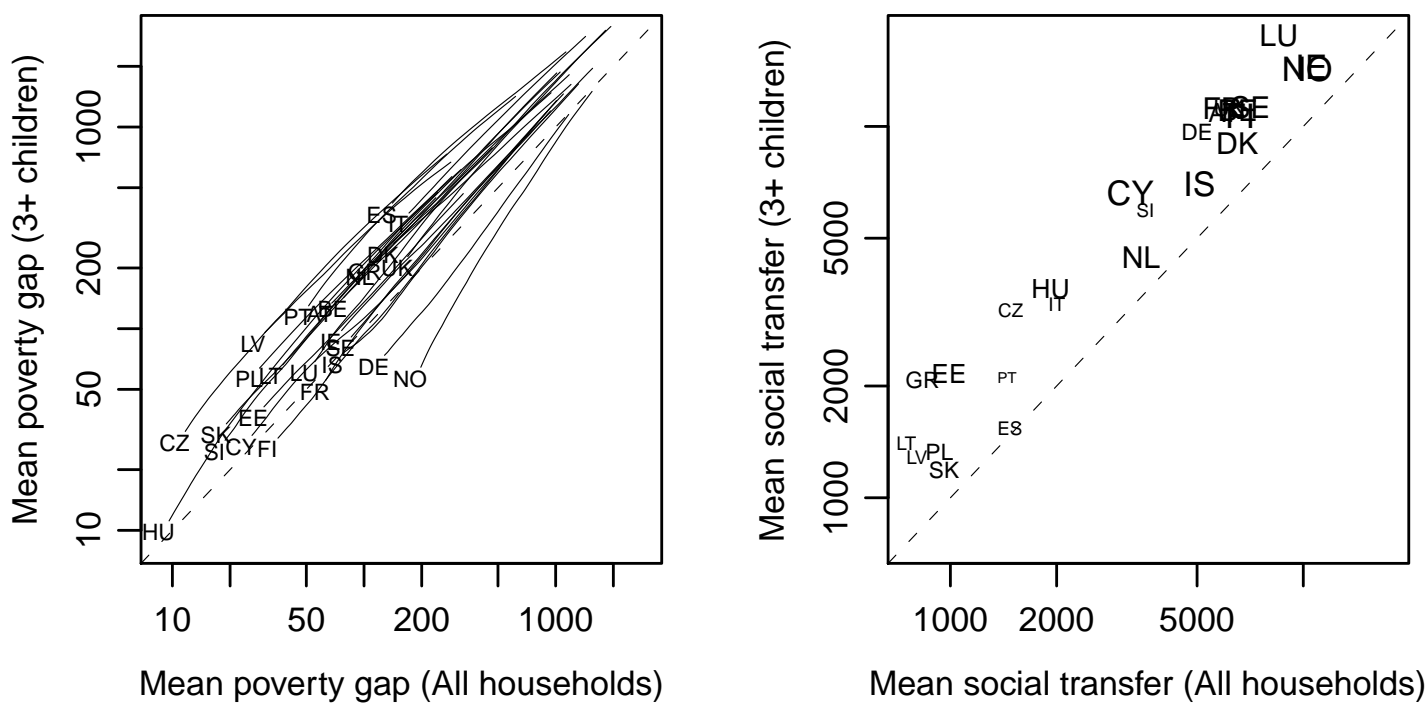

Figure 7: The mean poverty gap and the mean amount of social transfers paid to households with two adults and three or more children.

they are based on much smaller samples. We have no explanation for the anomalous behaviour of the curves for Luxembourg (absolute scale) and Norway (relative scale).

Next we study the social transfers to households with two adults and at least three children. These subsamples form between 3.9\% (Portugal) and 17.4\% (Iceland) of the national samples. Figure 7 summarises the size of the poverty gap as a function of the poverty threshold and the amounts of social transfers to these subsamples. The mean poverty gap for these subsamples is smaller than the overall mean for most countries and for all threshold percentages. Notable exceptions are Norway and Germany, but the mean poverty gap is smaller for the subsample than overall for part of the range of the threshold percentages also for Finland and France, although only by a narrow margin.

In the right-hand panel the mean amounts of social transfers are compared for the subsample and the entire national sample. The sizes of the symbols are proportional to the square roots of their proportions in the national samples, but the coefficient used is different from that in Figure 5, because large households are much more frequent than single-parent households in several countries (6.5 times in Cyprus). Only Latvia has more single-parent households $(6.2 \%)$ than households with three or more children $(4.5 \%)$. In all countries, the mean amount of social transfers for a household 
with many children exceeds the national mean, by the smallest margin in Spain and Slovakia. The clump of indistinguishable symbols in the diagram comprises Austria (9.5\%), Belgium (11.4\%), Finland (16.7\%), France (14.1\%), Sweden (12.7\%) and the UK (8.3\%), for which the national mean amounts are 6000-7000 Euro, and the means for the subsample around 11000 Euro. The pairs of amounts for Ireland and Norway are also very similar, around 10500 and 14500 Euro for their respective samples and subsamples.
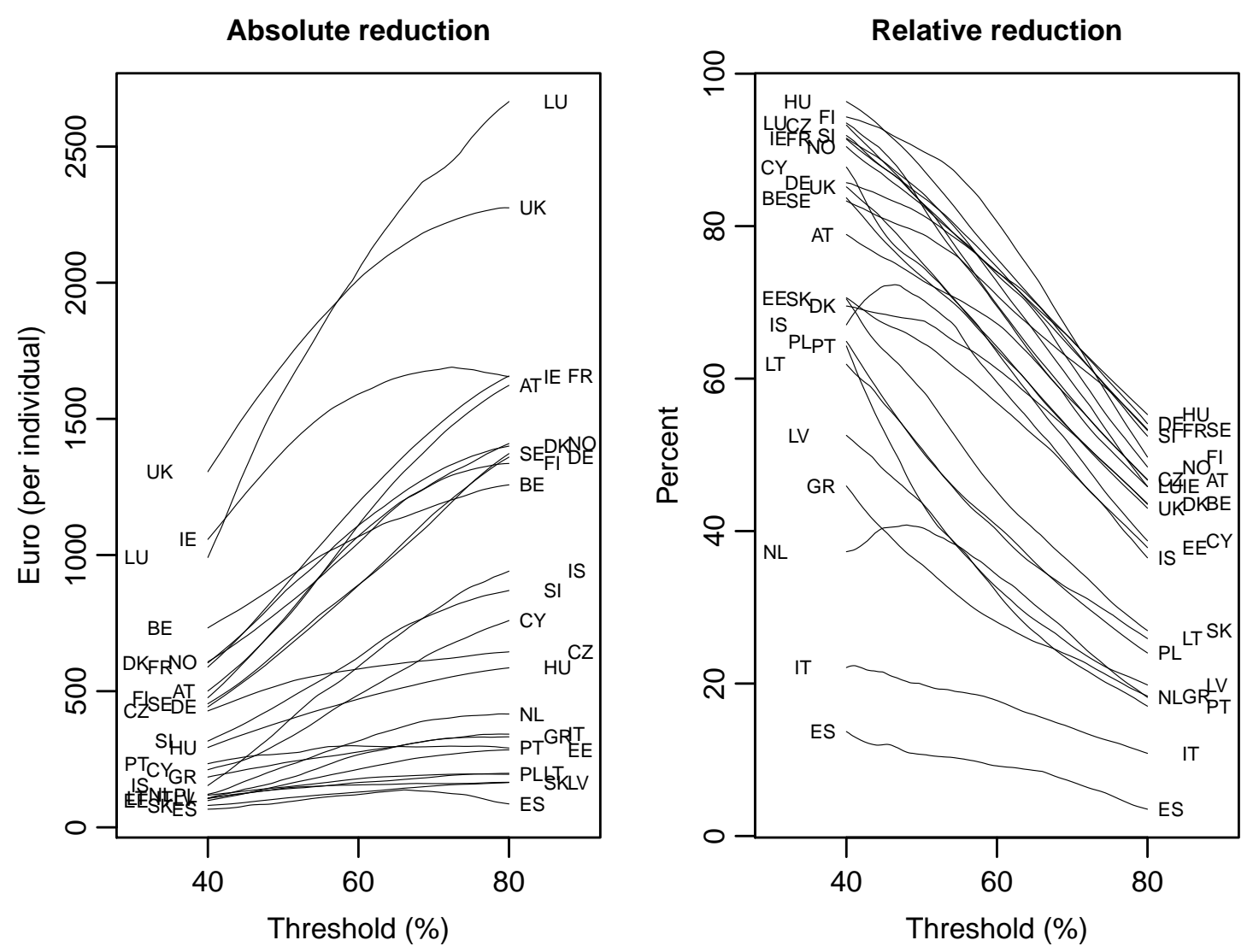

Figure 8: The absolute and relative reduction of the mean poverty gap among the single-parent households in the countries in EU-SILC.

Figure 8 displays the absolute and relative reduction curves for the (two-parent) households with three or more children. In common with Figure 6, the UK and Ireland have high absolute reductions, although for high threshold percentages Luxembourg has the highest reduction. The East European and Mediterranean countries tend to have small absolute reductions, but so does the Netherlands throughout the range and 
Iceland for the lowest threshold percentages. Spain and Italy, followed by Greece for threshold percentages of $45-60 \%$, have the smallest relative reductions.

\section{Conclusion}

Our main objective is to identify how well the social transfers fulfill the role of alleviating poverty so following an analysis of the contributions made by the social transfers to the household income, we defined two characteristics, the potential and the effectiveness of the social transfer system. The potential assesses how much of the poverty (or low eHI) could be removed by an ideal allocation of the funds in the social transfers. The effectiveness describes how close the current allocation is to this ideal. We concluded that the Scandinavian and central European countries are closer and the countries at the Mediterranean further from this ideal. The amount of social transfers per capita relative to the median eHI shows that the social transfers are on average very modest in Greece (8.3\% of the median eHI), Hungary (48.9\%) and Ireland (47.7\%) have the most generous social transfers. In one hand, the analysis of the potential of the social transfer systems shows that for the lowest poverty threshold, the potential exceeds $100 \%$ for all the countries. This means that, if allocated with purpose, the social transfers in these countries could easily raise every households eHI. The social transfers in Norway, Sweden and Slovenia could raise the minimum to a level even above $80 \%$ of the median eHI. In the other hand, the effectiveness of the systems points out that UK is uniformly the most effective, followed by Ireland for almost the entire range of threshold percentages and Czech Republic for a narrow range around 80\%. The lowest effectiveness is attained by Italy for the threshold percentages up to just above $70 \%$, for Cyprus up to $60 \%$, and for Latvia and Spain for threshold percentages above $70 \%$. We conclude that in general, for any given value of the potential, the social transfers in the countries in the north and west of Europe are more effective than in the south and in the three former Soviet republics. The systems in the countries in the central Europe are about as effective as the systems in the Scandinavian countries, but have a smaller potential. Except for Cyprus, the systems in the southern European (Mediterranean) countries have a low potential, and all of them have low effectiveness. 
The stability of the potential and effectiveness across time (years) is left for future research.

The analyses for subpopulations show some differences between the reduction of the mean poverty gap among single-parent households and households with many children and the reduction for the entire population. In first term, the mean poverty gap of the single-parent households exceeds the overall mean poverty gap in the country with the only exception of Denmark. In second term, the mean amount of social transfers paid to single parent-households is smaller than the overall mean for several countries. The analysis of social transfers to households with two adults and at least three children shows that the mean poverty gap for the subsample is smaller than the overall mean for most countries and for all threshold percentages, with the exceptions of Norway and Germany. In all countries the mean amount of social transfers for a household with many children exceeds the national mean.

\section{References}

Atkinson, A. B. (1995). Incomes and the Welfare State. Cambridge University Press, Cambridge, UK.

Atkinson, A. B. (2000). A European social agenda: Poverty benchmarking and social transfers. EUROMOD Working Paper No. EM3/00, Luxembourg.

Beckerman, W. (1979a). The impact of income maintenance payments on poverty in Britain. The Economic Journal 89, 261-279.

Beckerman, W. (1979b.) Poverty and the impact of income maintenance programmes. Geneva: International Labour Office.

Bibi, S., and Duclos, J.-Y. (2009). A comparison of the poverty impact of transfers, taxes and market income across five OECD countries. Unpublished manuscript.

Caminada, K., and Goudswaard, K. (2009). Social expenditure and poverty reduction in the EU15 and other OECD countries. Department of Economics Research Memorandum 2009.02, Leiden University, the Netherlands, and MPRA Paper No. 20138, Munich, Germany. 
Cohen-Solal, M., Montigny, P., and Saunier, J.-M. (1999). Les transferts sociaux en Europe, etudes et rèsultats, No. 5. Ministére de l'Emploi et de la Solidaritè. Paris, France.

Duncan, J. G., Gustafsson, B., Hauser, R., Schmauss, G., Messinger, H., Muffels, R., Nolan, B., and Ray, J.-C. (1993). Poverty dynamics in eight countries. Journal of Population Economics 6, 215-234.

Eardley, T., Bradshaw, J., Ditch, J., Gough, I., and Whiteford, P. (1996). Social assistance in OECD countries: Synthesis Report. HMSO, London.

Esping-Andersen, G. (1990). The Three Worlds of Welfare Capitalism. Princeton University Press, NJ.

Eurostat (2009). Poverty and social exclusion: Monetary poverty sustainable development indicators. Eurostat Metadata, http://epp.eurostat.ec.europa.eu/cache/ITY_SDDS/EN/tsdsc100_base.htm .

Luxembourg.

Eurostat (2010). Combating poverty and social exclusion. A Statistical portrait of the European Union. Eurostat Statistical Books, Luxembourg.

Hagenaars, A., de Vos, K., and Zaidi, M. A. (1994). Poverty statistics in the late 1980s: Research based on micro-data. Office for Official Publications of the European Communities. Luxembourg.

Hagenaars, A. J. M., and van Praag, B. M. S. (1985). A synthesis of poverty line definitions. Review of Income and Wealth 31, 139-145.

Hölsch, K., and Kraus, M. (2004). Poverty alleviation and the degree of centralization in European Schemes of social assistance. Journal of European Social Policy, 14 143165.

Longford, N. T., and Nicodemo, C. (2009). A sensitivity analysis of poverty definitions. IRISS Working Paper Series 2009-15, CEPS/INSTEAD, Differdange, Luxembourg. Marlier, E., Cohen-Solal, M., and Terraz, I. (1999). Les transferts sociaux et leurs effets redistributifs dans l'UE. Statistiques en Bref, Theme 3, 13/99. Luxembourg. 
Morissens, A., and Sainsbury, D. (2002). European anti-poverty policies in the 1990s: toward a common safety net? Maxwell School of Citizenship and Public Affairs. Syracuse University, NY. Working Paper No. 307.

Saalvedra, B., Nolan, B., and Smeeding, T. (Eds.) (2009). The Oxford Handbook of Economic Inequality. Oxford University Press, Oxford, UK.

Authors:

N. T. Longford, SNTL and Departament d'Economia i Empresa, Universitat Pompeu Fabra, Ramon Trias Fargas 25-27, 08005 Barcelona, Spain; email: NTL@snt1.co.uk. C. Nicodemo, Departament d'Economia Aplicada, Universitat Autònoma de Barcelona, Campus Bellaterra, 08193 Cerdanyola del Vallès, Spain; email:

catia.nicodemo@upf .edu 